\title{
Abordagens não dicotômicas do desenvolvimento: o posicionamento estratégico de atores vis-a-vis a abordagem ator-orientada
}

\author{
Cláudio Machado Maia ${ }^{1}$
}

\begin{abstract}
Resumo
Este estudo apresenta a temática da mudança social sob o viés do processo de desenvolvimento. Para esta abordagem, construiu-se um quadro teórico com conceitos, parâmetros e indicadores, com a finalidade de aferir conhecimentos para compreender o comportamento dos atores dessa mudança. Nesta construção teórico-metodológica, o desenvolvimento realça a articulação entre instituições e organizações ligadas às práticas empregadas nesse processo. O desenvolvimento não é entendido como um dom adquirido por certos países, regiões ou grupos sociais, definido e acabado, mas se constitui uma construção social que está sujeita a mudanças, conflitos e compromissos, diferentes representações políticas e culturais, conduzindo para um ou outro sentido. Ao distinguir o desenvolvimento em abordagens exógenas, endógenas e alternativas, volta-se à questão da ação individual e da estrutura social, para, dessa forma, buscar entender as noções de ator-rede, ator individual e ator social como categorias fundamentais de análise na investigação. Nessa evolução teóricoestrutural, para melhor apreender e compreender o conceito de ator integrado e natural, sugere-se considerar o ator social como um lócus de decisão e ação, cuja ação é apenas em parte uma consequência das suas decisões. A definição de ator é ampla, abrangendo não só o indivíduo humano, mas se estendendo a empresas, organismos estatais, organizações, associações e a todas as entidades capazes de tomar decisões e atuar em conformidade.
\end{abstract}

Palavras-chave: Mudança social. Desenvolvimento. Ação. Ator social. Estrutura.

\begin{abstract}
This study presents the theme of social change under the bias of the development process. For this approach a theoretical framework was constructed, with concepts, parameters and indicators, with the purpose of assessing and evaluating the behavior of the actors. In this theoretical-methodological construction, the analysis of development highlights the articulation between institutions and organizations linked to development practices. Development is not understood as a gift acquired by certain countries, regions or social groups, defined and finished, but it constitutes a social construction that is subject to changes, conflicts and compromises, different political and cultural representations, leading in one or the other sense. By distinguishing development from exogenous, endogenous and alternative approaches, one turns to the question of individual action and social structure, in order to seek to understand the notions of actor-network, individual actor and social actor as fundamental categories of analysis in research. In this theoretical-structural evolution, it is concluded that in order to better understand and understand the concept of integrated and natural actor, it is suggested to consider the social actor as a locus of decision and action, where action is only in part a consequence of the decisions of the actor. The definition of actor is broad, encompassing not only the human individual, but extending to companies, state agencies, organizations, associations and all entities capable of taking decisions and acting accordingly.
\end{abstract}

Keywords: Social change. Development. Action. Social actor. Structure.

\footnotetext{
${ }^{1}$ Doutor em Desenvolvimento Rural. Professor do Programa de Pós-Graduação em Políticas Sociais e Dinâmicas Regionais da Universidade Comunitária da Região de Chapecó (UNOCHAPECÓ). claudiomaia.dr@hotmail.com
} 


\section{Contexto global}

Durante a Guerra Fria, o mundo vivia diante de uma ordem internacional, tendendo à estabilidade e voltada essencialmente ao equilíbrio do sistema. Um sistema polarizado por duas potências e que não levou a uma guerra devido à adoção de uma política defensiva por ambas as partes, tal como uma política de contemporização e respeito entre si e suas respectivas zonas de influência, sobretudo na tentativa de restaurar e preservar o equilíbrio entre as duas potências.

O fim da Gerra Fria não desencadeou uma nova ordem internacional, mas uma nova estabilidade sistêmica ainda não consolidada, cuja característica principal é a despolarização. Não existindo mais uma potência ou conjunto de potências que possam constituir um pólo de oposição aos EUA, sobretudo em matéria de organização do mercado, de sistema político, de liderança ou de objetivos militares, a definição da estabilidade sistêmica e da paz passou a depender de construções ad hoc, cada caso passou a ser um caso. O fim do automatismo da definição de estabiliade e a ameaça à paz, na eminência de conflito internacional, formam-se coalizões, sendo que as formadas no início de um conflito não são necessariamente as mesmas que se mantêm no fim. Em tal contexto, observa-se que, por exemplo, conflitos que possam afetar a estabilidade e pôr em risco a paz internacional não são automaticamente limitados pela intervenção das superpotências, podendo perpetuar ou mesmo agravar seus efeitos desestabilizadores. Sendo assim, os limites da autonomia se ampliaram e, consequentemente, tem-se um mundo menos estável e menos previsível, um desafio para o exercício da política externa (ALBUQUERQUE, 2005, p. 61-62).

Albuquerque (2005, p. 77-80) apresenta duas hipóteses para a nova configuração do poder mundial. Entretanto, nessa reflexão, apresenta-se uma perspectiva mais geral e linear para fins de contextualizações. A primeira, a presença de um colegiado de potências, formado por um conjunto de países que manteriam o equilíbrio, respeitando suas respectivas áreas de influência, podendo haver a coexistência, desde que em equilíbrio, de várias potências numa mesma região. A segunda, a hipótese de uma hegemonia dissociada, cuja ordem mundial se caracterizaria pela liderança dos Estados Unidos, por sua supremacia militar, mas não por uma supremacia incontestável no plano econômico, sendo que as demais potências ficariam dispostas em três dimensões, sobretudo as do comércio, da 
política e da defesa, em diversos graus de cooperação, rivalidade e confrontação com os EUA e entre si.

Um dos principais processos que atua na configuração das relações internacionais, a transnacionalização ${ }^{2}$, provoca o aparecimento simultâneo de novos atores e de novas questões e estratégias de atuação, nas quais esses novos atores, juntamente com os já existentes, se organizam. Tais novos atores são novos estados, que resultaram do desmembramento do império soviético e de estados do Terceiro Mundo, que expandiram indevidamente, prevalecendo-se dos impasses da Guerra Fria. Também são novas configurações paraestatais de poder, tais como o crime organizado internacional, alguns tipos de movimentos guerrilheiros e terroristas, movimentos étnico-nacionalistas, algumas organizações não-governamentais radicais, adeptas da ação direta. Também são, ainda, as organizações "não-governamentais" multinacionais, empresariais ou não. "As novas questões da agenda global são novas apenas em sua expressão internacional, pois na verdade sempre existiram em sua expressão doméstica" (ALBUQUERQUE, 2005, p. 83).

\section{Introduzindo uma estratégia de análise}

Esta reflexão teórica e metodológica procura apresentar uma abordagem que serve como modelo de análise da mudança social, uma abordagem que procura focar as relações, mais do que os extremos, e que chama a atenção para o fato de as mudanças social, econômica, política e cultural não poderem ser compreendidas com a simples referência a condições estruturais, muitas vezes remetidas apenas para forças externas (determinação externa), resultantes de mecanismos de mercado ou da ação do estado, que constrangem e/ou potenciam a ação dos indivíduos.

Busca-se explicar, por exemplo, que dada a diversidade estrutural, existem respostas diferentes em situações estruturais semelhantes, ou, em outras palavras, há grande heterogeneidade de soluções encontradas na escala local e em nível da ação individual. E,

\footnotetext{
${ }^{2}$ Conforme Paulet (2009), um aumento dos investimentos e das implantações no exterior. Enquanto que Albuquerque (2005) afirma que é um fenômeno permanente da história do mundo civilizado, mas que se acelerou e tomou dimensões globais nas últimas décadas. A transnacionalização é a propriedade que tem certos fenômenos de projetar seus efeitos através das fronteiras nacionais. Sua generalização e aceleração vertiginiosas, que a tornam "instantânea" para todos os efeitos práticos, golpeiam profundamente as prerrogativas dos estados nacionais como atores exclusivos das relações internacionais.
} 
também, que tal diversidade só pode ser então atribuída à ação dos indivíduos, à recomposição de perfis sociais e/ou à emergência de novos perfis. E que terá que ser reconhecida pelos indivíduos sua capacidade reflexiva e de ação (autonomia ou margem de manobra), a qual lhes permite tomar consciência dos seus interesses, formular objetivos e definir estratégias para os atingir. Mesmo em condições de limitação e condicionantes, os indivíduos não podem ser vistos como sujeitos passivos ou vítimas da mudança planejada (de cima para baixo), nem "simplesmente" como aqueles que se limitam a seguir um conjunto de regras e convenções.

Valorizar o fato de que a ação individual, embora Ihe seja atribuída uma importância central, só pode ser compreendida quando integrada no contexto social e natural, que começa por ser local (relações pessoais de copresença), mas que inclui outros níveis e escalas espaciais e temporais. Defende-se, então, partir dos conceitos de ação individual, de ator e de estrutura social, bem como de outras noções auxilares, que permitam esclarecer o campo onde se encontra a problemática, para procurar, depois, estabelecer a relação entre ação individual e estrutura social, ou seja, saber como relacionar a ação e a interação com as estruturas sociais e econômicas mais amplas.

\section{Mudança social: um entendimento do processo de desenvolvimento}

Faz-se necessário introduzir um quadro teórico, baseado no conceito de desenvolvimento, para poder explicar aspectos particulares da mudança, aduzindo parâmetros e indicadores (variáveis) para a sua avaliação e valorização social. Esta visão procura compreender o comportamento dos atores, ao mesmo tempo que permite avaliar consequências intencionais ou não intencionais da ação social (a ação em contexto) (VEIGA, 2005, p. 67).

Acrescente-se ainda que a análise do desenvolvimento realça a articulação entre as instituições e organizações (interação entre atores) ligadas às práticas de desenvolvimento, como política pública ou para-pública, e o conjunto dos atores locais e não locais, tomados

como destinatários dessas práticas. À volta das representações do desenvolvimento, constroem-se redes de relações que condicionam e/ou potencializam as ações dos atores e, em termos coletivos, promovem dinâmicas ou bloqueios à melhoria do bem-estar local. 
A análise poderá naturalmente separar as teorias do desenvolvimento das políticas e práticas. No entanto, como ambas são intimamente ligadas, de cada opção teórica, decorre de imediato uma posição específica quanto às políticas e práticas mais adequadas para atingir estágios superiores de desenvolvimento.

Desde o seu aparecimento, nos anos 1950, o conceito de desenvolvimento tem sido objeto de intenso debate, o que lhe tem agregado novas dimensões e aplicações, sendo hoje um conceito multidimensional e pluridisciplinar. As novas dimensões do conceito têm permitido uma maior aderência à realidade, mostrando que o desenvolvimento, enquanto processo social, não é também unilinear, com um sentido único de progresso social e econômico, mas pode ter evoluções contraditórias, desenvolvimento, não desenvolvimento, antidesenvolvimento. Portanto, o desenvolvimento não é um dom definitivo e acabado, adquirido por certos países, regiões ou grupos sociais, mas sim uma construção social sujeita a mudanças, conflitos, compromissos, diferentes representações políticas e culturais, que podem conduzir para um ou outro sentido.

Entretanto, pondo de lado uma análise mais geral sobre o conceito de desenvolvimento e sua evolução, já ensaiada pelos clássicos e vários outros autores, a opção tomada na abordagem aqui analisada considera como as mais importantes as que relacionam desenvolvimento e território no contexto rural; as relações entre os vários níveis e escalas espaciais, local/global, nos conceitos de desenvolvimento exógeno e de desenvolvimento endógeno, e as relações entre social/natural no conceito de desenvolvimento sustentável. Por outro lado, o conceito de desenvolvimento local está, obviamente, presente na abordagem do desenvolvimento.

3.1 Abordagem dominante nos anos de 1950 e 1960. O modelo de desenvolvimento exógeno

A abordagem dominante, nos anos 1950 e 1960, e que chegou aos anos 1980, concebia o desenvolvimento do meio rural e da sua atividade econômica predominante, a agricultura, como resultado apenas de um impulso exógeno de natureza essencialmente econômica e tecnológica. Mas, subjacente a essa posição, estava uma concepção do espaço como um mero suporte, sob o qual se confrontavam forças, funções econômicas, que definiam as localizações e, por essa via, a estrutura e a hierarquização dos espaços 
econômicos. Pecquer e Silva (1989) designam esta concepção do espaço como paradigma funcionalista. Conforme os autores (1989), as abordagens iniciais que se incluem neste paradigma funcionalista privilegiavam visões dualistas da economia, que opunham o setor moderno (urbano-industrial) ao setor atrasado (rural). Em tais modelos, o crescimento econômico processava-se, numa primeira fase, com a transferência de mão de obra e, eventualmente, de capital do setor tradicional para o setor moderno, com a agricultura desempenhando uma função de fornecimento de alimentos baratos aos centros urbanos em expansão.

Acreditava-se que as desigualdades de rendimentos entre as regiões, os desequilíbrios regionais, seriam ultrapassados pelos efeitos da difusão (trickle down), em sentido inverso, do setor moderno para o setor tradicional, que se verificariam nas fases seguintes do processo de crescimento econômico.

O diagnóstico era claro: os problemas de desenvolvimento rural (o rural reduzido ao agrícola) ou de desenvolvimento regional reduzir-se-iam a problemas de "marginalidade", entendida com frequência, em termos geográficos, como sinônimo de zonas periféricas ou remotas. No caso da agricultura, os problemas eram agravados devido à abundância de mão de obra, o que conduzia a uma produtividade muito baixa e, consequentemente, a níveis de vida também baixos. Acrescente-se, também, que as diferenças em termos tecnológicos, socioeconômicos e culturais com as zonas urbano-industriais eram também enormes, o que permitia classificar as zonas rurais como atrasadas.

Em termos de política regional e política agrícola, por exemplo, as políticas eram setoriais ${ }^{3}$, propostas que consistiam essencialmente na concessão de incentivos às empresas e na realização de infraestruturas públicas; no aumento da mobilidade de trabalho e do capital; e na criação de centros de crescimento, seguindo (ou promovendo) uma hierarquia de centros urbanos (teoria dos lugares centrais), assim como a criação de serviços públicos de extensão rural, articulados com a investigação, experimentação e demonstração, também públicas, inscreviam-se nesta lógica de facilitar a transferência tecnológica e outras mudanças induzidas a partir do exterior. As práticas de políticas designadas por

\footnotetext{
${ }^{3}$ Neste modelo, a política regional era uma política nacional, construída de cima para baixo, que procurava resolver o problema das assimetrias regionais per si, não integrando a outras políticas setoriais, caso da política agrícola, daí poder considerar-se como mais uma política setorial.
} 
modernização da agricultura, a partir de agências estatais, consistiam em programas de intervenção externa.

\subsection{Uma abordagem complementar. O desenvolvimento endógeno}

A insatisfação com os modelos anteriores conduziu ao aparecimento, nos anos de 1980, de abordagens complementares ou mesmo alternativas, tal como novos conceitos ou novas dimensões do mesmo conceito, seguindo o pressuposto de que o desenvolvimento deve partir dos recursos específicos - humanos, naturais, culturais de um determinado território. Autores como Pecquer e Silva (1999), Requier-Desjardins (1999) falam de um paradigma territorialista, oposto ao paradigma funcionalista, paradigma que define 0 espaço-território, assente numa sociocultura comum, num espaço apropriado, onde se formulam estratégias baseadas na solidariedade existente em nível local. As abordagens endógenas do desenvolvimento são muito diversificadas, não constituindo um modelo teórico único, alternativo ao modelo exógeno.

A introdução de uma nova representação do espaço, o espaço local (espaçoterritório), e a articulação entre as várias escalas espaciais (do local ao global), em alternativa à representação em uma única escala, a nacional, permitiu revelar fenômenos econômicos, sociais, políticos e culturais importantes que antes estavam escondidos, ou eram ignorados, ou tomados como vestígios do passado, entraves ao processo irreversível de nacionalização do espaço. É precisamente quando esta nacionalização enfraquece perante à crescente importância da escala global, globalização (em níveis econômico e financeiro), que os fenômenos localizados se revelam e lhes é reconhecida importância teórica.

Conforme Veiga (2005, p. 72), apenas para indicação, quatro principais correntes podem ser identificadas sob a vasta designação de abordagens do desenvolvimento endógeno, sendo que, embora muito abrangentes, recebem as designações de distritos industriais; de desenvolvimento e planejamento regional; de terceiro setor; e de desenvolvimento sustentável. 
Tabela 1 - Modelos e abordagens do desenvolvimento

\begin{tabular}{|l|l|l|}
\hline \multicolumn{1}{|c|}{ Dimensões } & $\begin{array}{l}\text { Modelo de desenvolvimento } \\
\text { exógeno }\end{array}$ & \multicolumn{1}{c|}{$\begin{array}{c}\text { Modelo de desenvolvimento } \\
\text { endógeno }\end{array}$} \\
\hline Princípios-chave & $\begin{array}{l}\text { Economias de escala e } \\
\text { concentração }\end{array}$ & $\begin{array}{l}\text { Recursos específicos de uma } \\
\text { área: humanos, naturais, culturais }\end{array}$ \\
\hline Força dinâmica & $\begin{array}{l}\text { Pólos de crescimento urbano } \\
\text { As principais forças de } \\
\text { desenvolvimento concebidas } \\
\text { como exteriores às áreas } \\
\text { rurais }\end{array}$ & Iniciativa local e de empresas \\
\hline Sentido da dinâmica & $\begin{array}{l}\text { A partir de cima } \\
\text { (top down) } \\
\text { Paradigma funcionalista }\end{array}$ & $\begin{array}{l}\text { A partir de baixo } \\
\text { (bottom up) } \\
\text { Paradigma territorialista }\end{array}$ \\
\hline Funções das áreas rurais & $\begin{array}{l}\text { Alimentos e outras } \\
\text { produções primárias para } \\
\text { expandir a economia urbana }\end{array}$ & $\begin{array}{l}\text { Economia de serviços diversos } \\
\text { Problemas de } \\
\text { desenvolvimento rural }\end{array}$ \\
$\begin{array}{l}\text { Baixa produtividade e } \\
\text { acessibilidade }\end{array}$ & $\begin{array}{l}\text { Capacidade limitada de áreas e } \\
\text { grupos sociais para participarem } \\
\text { na atividade econômica e no } \\
\text { desenvolvimento }\end{array}$ \\
\hline $\begin{array}{l}\text { Alvos do desenvolvimento } \\
\text { rural }\end{array}$ & $\begin{array}{l}\text { Industrialização da } \\
\text { agricultura e especialização } \\
\text { Encorajamento da } \\
\text { mobilidade do trabalho e do } \\
\text { capital }\end{array}$ & $\begin{array}{l}\text { Construção da capacidade } \\
\text { (formação profissional, } \\
\text { instituições e infraestruturas) } \\
\text { Ultrapassar a exclusão social }\end{array}$ \\
\hline Relações com o ambiente & $\begin{array}{l}\text { Crescimento econômico em } \\
\text { primeiro lugar }\end{array}$ & $\begin{array}{l}\text { Sustentabilidade } \\
\text { Consequências distributivas do } \\
\text { desenvolvimento }\end{array}$ \\
\hline
\end{tabular}

Fonte: Veiga (2005, p. 83).

\section{Uma abordagem alternativa}

As abordagens mais recentes sobre desenvolvimento contestam as posições parcelares em torno de dualismos teóricos, tais como exógeno/endógeno, social/natural, por oferecerem uma polaridade artificial, defendendo análises que privilegiam as relações entre os dois extremos.

Agora, considerando que muitas formas de desenvolvimento envolvem tanto recursos locais como não locais, uma questão que pode ser crucial é a de saber como é que os circuitos locais de produção, consumo e significado, articulam-se com os circuitos não locais. Então, entender como ocorre a interação entre as forças locais e as forças externas no controle dos processos locais de desenvolvimento torna-se uma questão interessante a se analisar. 
Tais posições são coerentes com a noção de lugar ou território, como um ponto de encontro de interações sociais de vários níveis e escalas espaciais, as quais podem vir a ser adotadas, conforme o tipo e escala de análise que estiver sendo realizada, podendo reunir duas dimensões - a endógena (territorial), definida pelas características locais, e a exógena (funcional), na abertura ao exterior, na interação entre relações sociais e escalas espaciais.

Tão importantes quanto as características endógenas são o tipo e a qualidade das relações passíveis de ser estabelecidas com o exterior e que estão representadas na capacidade de auto-organização ${ }^{4}$ e de arranjo institucional ${ }^{5}$ em nível local. Como afirma Veiga (2005, p. 84), assim como o conceito de sustentabilidade tem contribuído para quebrar a dicotomia social/natural, o da abordagem ator-rede tem sido utilizado também para ultrapassar o caráter artificial do dualismo endógeno/exógeno.

Considera-se, empiricamente, um esquema analítico baseado na formação de redes como forma alternativa de alocação de recursos às do Estado (hierarquia) e do mercado (anarquia), cuja diferença se concentra no fato de uma privilegiar a associação (o poder de associação) e a cooperação (o caso das redes), e não a decisão administrativa ou a concorrência.

No caso deste tipo de redes, a questão do espaço assume nova importância já que as suas práticas necessitam proximidade espacial, independentemente dos contextos locais e regionais. Entretanto, a questão em torno da escala pode ser ultrapassada muito devido às conexões que os atores possam estabelecer entre eles. As redes, então, contribuem também para atenuar as fronteiras entre o estado e o mercado, ganhando importância as suas relações, sobretudo, com a capacitação de associações intermediárias entre o estado e o mercado (grupo de empresas, associações empresariasi, sindicatos, associações civis, etc) (VEIGA, 2005, p. 85). Então, medir o processo de desenvolvimento pode ser compreendido como buscar-se uma avaliação empírica do sentido (ou sentidos) do processo de mudanças social, econômica, política, natural e cultural, situando-se na perspectiva de superar as visões dicotômicas do desenvolvimento.

\footnotetext{
${ }^{4} \mathrm{O}$ conceito de auto-organização é retirado da moderna teoria evolucionista (neochumpeteriana). Ou seja, os agentes individuais estão necessariamente ligados a redes... que regulam o comportamento de cada agente através de mecanismos de feedback (positivos ou negativos). Tal fenômeno coletivo e cooperativo possui um papel importante na auto-organização de sistemas socioeconômicos (VEIGA, 2005, p. 84).

${ }^{5} \mathrm{~A}$ dimensao institucional deixa de ser um meio, entre outros de desenvolvimento (rural), para se transformar, ela própria, num objetivo a atingir. Liderança, representatividade e credibilidade em nível local e em relação a instituições ou agentes exógenos, constituição de formas de parcerias... (VEIGA, 2005, p. 84).
} 
Numa tentativa de síntese, pode-se entender que as abordagens teóricas do desenvolvimento, sobretudo as de conceito, modelos e práticas de desenvolvimento tem evoluído para abordagens mais integradas, sistêmicas, multidimensionais e pluridisciplinares, as quais contestam as visões dicotômicas que inicialmene caracterizavam o debate sobre desenvolvimento. Subjacente a qualquer abordagem sobre o processo de desenvolvimento, estão, naturalmente, a busca pelo estabelecimento das relações entre ação individual/estrutura social, e o foco no papel central dos atores e no reconhecimento de sua capacidade reflexiva e de ação, exigindo formas de participação e de construção da capacidade de articulação e desenvolvimento (local).

\section{A ação individual e a estrutura social}

Essencialmente, para se entender a abordagem ator-rede, deve-se compreender o conceito ou noções de ação (ou agencia) e de estrutura, sobretudo, saber que a relação entre eles implica a questão de como os indivíduos se integram em relações sociais mais amplas e estruturas.

Inicialmente, algumas noções conceituais são essenciais ao entendimento de uma abordagem que se propõe a refletir sobre ação individual e estrutura social, compreender ação ou agencia e estrutura. Para Giddens (1996, p. 91), ação ou agencia é definida como "[...] o fluxo de intervenções causais, efetivas ou contempladas de seres corpóreos no processo contínuo dos acontecimentos do mundo". Entretanto, Veiga (2005, p. 46) apresenta dois pressupostos inerentes a tal conceito. $O$ primeiro postula que $O$ ator individual "[...] possa ter agido de outra forma". O segundo, que a parte que não depende da decisão do ator "[...] não condicione um futuro pré-determinado". Conforme Long e Ploeg (1994, p. 66), nessas condições, em termos gerais, a noção de agencia considera o ator individual como capaz de processar a experiência social e buscar alternativas de enfrentar a vida, mesmo sob extremas formas de coerção. E, mesmo sob limites de informação, sobretudo de incertezas e de outras restrições que possam existir ${ }^{6}$, os atores sociais são "[...] detentores de conhecimento" e "capazes".

\footnotetext{
${ }^{6}$ Restrições materiais, normativas ou político-econômicas existentes. 
Dada a importância do conceito de ator, sobretudo para melhor entendê-lo integrado ao meio social e natural, sugere-se considerar ator social "[...] como um lócus de decisão e ação, onde a ação é em parte uma consequência das decisões do ator" (HINDESS, 1986, p. 117 apud VEIGA, 2005, p. 46).

Por outro lado, também há dois aspectos a considerar. O primeiro é que por ator social entende-se não apenas o indivíduo humano, mas também empresas, organismos estatais, organizações, associações, enfim, todas as entidades capazes de tomar decisões e atuar em conformidade ${ }^{7}$.

Conforme Long e Ploeg (1994),

\begin{abstract}
... a 'agencia' requer capacidades de organização e não é simplesmente o resultado de certas capacidades cognitivas, poderes persuasivos ou formas de carisma que um indivíduo possa ter. A capacidade de influenciar os outros ou de transmitir uma ordem (por exemplo, fazer com que os outros aceitem determinada mensagem) reside fundamentalmente nas "ações de uma cadeia de acontecimentos, que cada um traduz de acordo com seus próprios projetos ... e o poder é composto, aqui e agora, pela associação de muitos atores em um dado esquema político e social' (LATOUR, 1986, p. 264).
\end{abstract}

Por outras palavras, a agencia (e o poder) depende crucialmente da emergência de uma rede de atores que se tornam parcialmente, embora quase nunca completamente, envolvidos nos projetos e práticas de outro indivíduo ou indivíduos. Por conseguinte, a agencia efetiva requer a geração/manipulação estratégica de uma rede de relações sociais e a canalização de itens específicos (como reivindicações, ordens, bens, instrumentos e informação) através de certos pontos fundamentais de interação (LONG; PLOEG, 1994).

O segundo aspecto na definição de ator é que "[...] os atores tomam decisões e atuam em conformidade, mas fazem-no sob condições que apenas parcialmente estão sob o

\footnotetext{
${ }^{7}$ As entidades que não tenham meios para tomar decisões, embora possam existir atores que as digam representar, tais como as categorias sociais de classe, comunidade, sociedade, não são consideradas atores nesta definição. O território não pode ser considerado um ator, pois não é um lócus de decisão e ação único, não tendo uma função objetiva, não estando dotado de uma organização semelhante à das empresas ou de outros organismos. Nada permite demonstrar que há uma racionalidade coletiva que dotaria o território com capacidade estratégica. Logo, o território é visto, então, como um resultado que, embora possa ser identificável e não fraccionável, permanece imutável, provisório e inacabado (PECQUEUR, 1996, p. 15). Em contraste, a territorialidade é considerada um pressuposto, uma modalidade de comportamento estratégico próprio a cada indivíduo, pelo que é permanente e faz parte da essência do comportamento individual. Pecqueur (1996, p. 16) conclui ainda que mais importante que os territórios são as dinâmicas territoriais. Com a noção de territorialidade, procura repor "[...] o espaço vivido pelos atores" no centro do processo de desenvolvimento.
} 
seu controle, e na base de técnicas, modos de pensar e meios de ação disponíveis para eles" (MURDOCH, 1994, p. 7).

Estas concepções de ação e de ator social põem em questão o individualismo metodológico e as teorias da tomada de decisão nele baseadas. O comportamento dos atores não pode ser reduzido a uma racionalidade única, pura ou instrumental, ou simplesmente modelada ou previsível, já que está sempre sujeito a algum grau de indeterminação, por estar marcado pelo seu contexto e pela ação de outros atores ${ }^{8}$. Agora, a parte que não depende da decisão do ator, ou que não está sob o seu controle, leva ao segundo conceito, o de estrutura ou estrutura social.

Na perspectiva apresentada por Murdoch (1994, p. 6-7), estrutura social é o resultado das práticas estruturantes dos atores nas situações sociais ${ }^{9}$. Práticas essas que visam associar outros atores à volta de representações, interesses, estratégias, objetivos, tornados comuns por meio de um processo de "tradução", construindo-se, desse modo, redes de relações mais ou menos estáveis, onde tais redes passam, então, a condicionar, ou possibilitar a ação dos atores de forma desigual.

Metodologicamente, recomenda-se que, a partir da perspectiva de Murdoch (1994), busque-se seguir os atores e analisar as formas como estes constroem as redes de relações e, por sua via, as estruturas. Por outro lado, derivando da noção de estrutura, sobretudo de estrutura social, há outras definições que têm sido utilizadas para destacar, por exemplo, o papel das instituições na análise das ações individual e coletiva.

Entretanto, falar sobre instituições nos leva a considerar o que North (1990, p. 3 e p. 99) trata, respectivamente, como instituições e path of institutional change - a dinâmica impulsionada pela existência de incentivos e de constrangimentos que reforçam uma determinada direção para as ações dos indivíduos e organismos sociais, uma vez que esta

\footnotetext{
${ }^{8}$ Não se pode dizer que determinada ação de um ator é irracional, mas que ele poderia ter agido de outra maneira se tivesse tido outras informações, meios ou circunstâncias.

${ }^{9}$ Murdoch (1994) parte do "situacionismo metodológico" apresentado por Knorr-Cetina (1981), que considera a "interação em situações sociais" (ação em contexto) como a "unidade metodológica relevante" (KNORRCETINA, 1981, p. 8-9). Às situações sociais, presença imediata da interação frente a frente num contexto particular, é reconhecida uma realidade por si própria, com dinâmica e organização próprias, que não se pode prever com o reconhecimento dos atributos dos simples atores. Isto por duas razões. Primeiro porque o produto da ação individual está ligado a ocasiões particulares, ao meio social e natural onde ocorre, e a outros participantes na situação. Segundo, o comportamento social é contingente do comportamento dos outros (interação, reciprocidade e caráter situado da ação social). Assim, embora possa ser correto que só indivíduos são atores intencionais, a ação nasce do confronto de intencionalidades mais do que da sua existência singular.
} 


\author{
direção tenha sido adotada - uma dependência de caminho que considera a importância da \\ aprendizagem gerada por dinâmicas de longo prazo ${ }^{10}$. \\ Segundo North $(1991)^{11}$,
}

Institutions are the rules of the game in a society or, more formally, are the humanly devised constraints that shape human interaction. In consequence, they structure incentives in human exchange, whether political, social, or economic. Institutional change shapes the way societies evolve through time and hence is the key to understanding historical change (NORTH, 1991, p. 97).

\author{
Conforme enfatiza North (1991) $)^{12}$,
}

Institutions are the humanly devised constraints that structure political, economic and social interaction. They consist of both informal constraints (sanctions, taboos, customs, traditions, and codes of conduct), and formal rules (constitutions, laws, property rights). Throughout history, institutions have been devised by human beings to create order or reduce uncertainty in exchange (NORTH, 1991, p. 97)

Já Nuijten e Appendini (2002) apresentam uma reflexão ao concluir pesquisa sobre o papel das instituições em contextos locais:

\begin{abstract}
Al tener como objetivo ciertas instituciones u organizaciones específicas dentro de programas y proyectos de desarrollo, es importante una aproximación abierta y flexible que tome en cuenta las iniciativas locales, y que además contemple los grupos e intereses diversos, dando lugar a espacios amplios de negociación abierta e inclusiva. En esta perspectiva es importante definir las áreas, formas y niveles en que puede llevarse a cabo la intervención, ya que las instituciones se componen de diversos elementos a distintos niveles que van desde la comunidad y la aldea hasta las instancias gubernamentales y la legislación nacional. Así, las acciones a nivel local pueden articularse con programas públicos amplios, como programas educativos masivos, que en última instancia pueden ser medios para el "empoderamiento" de los grupos más pobres y una estrategia general para ampliar su participación en los ámbitos institucionales y organizativos locales (NUIJTEN; APPENDINI, 2002, p. 87).
\end{abstract}

${ }^{10}$ Embora cada indivíduo seja um ser único, todos os indivíduos são ligados por alguma coisa em comum valores, moral, cultura - que tem uma dependência ao longo da história. A chave para concluir a história é o tipo de aprendizado que o indivíduo numa sociedade adquire através do tempo. A transmissão do estoque acumulado de conhecimento, ao longo do tempo, lembra o termo Path dependence. Conforme North (1994), o termo é usado para descrever a força da influência do passado no presente e no futuro.

${ }^{11}$ As instituições são a regra do jogo na sociedade, ou mais formalmente, são constrangimentos humanamente inventados que moldam a interação humana. Consequentemente, elas estruturam incentivos na troca humana, seja política, social ou econômica. A mudança institucional molda os caminhos das sociedades, evoluindo através do tempo, e, a partir daí, a chave e o entendimento da mudança histórica.

${ }^{12}$ As instituições são constrangimentos criados que estruturam a interação política, econômica e social. As instituições consistem de dois tipos de constrangimentos - formais (sanções, tabus, costumes, tradições e códigos de conduta) e instituições informais (constituições, leis e direitos de propriedade). Durante a história, instituições têm sido criadas por iniciativas humanas para garantir a ordem, ou reduzir a incerteza nas trocas. 
A análise anteriormente apresentada por Nuijten e Appendini (2002, p. 87), de alguma maneira, lembra a leitura da Sociologia do Desenvolvimento numa perspectiva centrada no ator de Long (2007), onde:

\begin{abstract}
Una ventaja del enfoque centrado en el actor es que se empieza con el interés de explicar las respuestas diferenciales a circunstancias estructurales similares, aun cuando las condiciones parezcan más o menos homogéneas. Así se asume que los modelos diferenciales que aparecen son en parte creación colectiva de los actores mismos. Sin embargo, los actores sociales no deben figura como simples categorías sociales incorpóreas (basadas en la clase o algún criterio clasificatorio), o destinatarios pasivos de la intervención, sino como participantes activos que reciben e interpretan información y diseñan estrategias en sus relaciones con los diversos actores locales, así como con las instituciones externas y su personal. Las sendas precisas del cambio y su importancia para los implicados no pueden imponerse desde fuera, ni pueden explicarse por los mecanismos de alguna lógica estructural inexorable ${ }^{13}$ (LONG, 2007, p. 43).
\end{abstract}

Long (2007) afirma que os estudos nutridos pela perspectiva do ator tendem a enfatizar a racionalidade discursiva dos atores por conta da sua consciência prática, sendo que a racionalidade não é uma propriedade dos indivíduos e sim de discursos disponíveis, os quais formam parte do entorno cultural da prática social. Determina que a construção de agencia segue as concepções de racionalidade, poder e conhecimento, que são culturalmente variáveis e não podem ser separados das práticas sociais dos atores.

Como referenciado anteriormente, os conceitos orientados ao ator aspiram encontrar espaço para uma multiplicidade de racionalidades, desejos, capacidades e práticas, incluindo os associados com vários modos de instrumentalismo. A importância relativa dessas diversas ideias, sentimentos e maneiras de atuar, para dar forma aos componentes sociais e para provocar a mudança, só pode evoluir num contexto único e dependente de uma multiplicidade de componentes interconectados de recursos sociais, culturais e técnicos. Por outro lado, um ponto conceitual chave para a discussão em torno da sociologia do desenvolvimento, na perspectiva centrada no ator, é a questão da agencia. Muitos autores têm retrocedido para reconsiderar a natureza essencial e importante da "agencia humana", cuja noção "metateórica" está no coração de qualquer paradigma revitalizado do ator social e forma o eixo ao redor do qual giram os "planteamientos" que intentam reconciliar as noções de estrutura e ator (LONG, 2007, p. 48).

\footnotetext{
13 Como está implícito en el modelo de "periferia desarticulada" de De Janvry (1981) apud Long (2007, p. 43): "para un conocimiento más amplio de la postura crítica de la "lógica del capital" en el enfoque de De Javry y su argumento de que el Estado actúa como un instrumento para resolver las crisis de acumulación capitalista".
} 
Em geral, conforme Giddens (1984, p. 1-16 apud Long, 2007, p. 48), a noção de agencia atribui ao ator individual a capacidade de processar a experiência social e desenhar maneiras de lidar com a vida. Dentro de limites de informação e outras restrições (por exemplo, físicas, normativas ou político-econômicas), os atores ${ }^{14}$ sociais possuem "capacidade de saber" e "capacidade de atuar". Intentam resolver problemas, aprendem como intervir no fluxo de eventos sociais ao seu redor e, em certa medida, estão em torno de suas próprias ações, observando como outros reagem à sua conduta e tomando nota das várias circunstâncias contingentes.

\begin{abstract}
La 'agencia' está encarnada en las relaciones sociales, y solo puede ser efectiva a través de ellas. No sólo es el resultado de poseer ciertos poderes persuasivos o formas de carisma; la habilidad de influir en otros o dejar pasar una orden - por ejemplo, para conseguir que los otros acepten un mensaje particular - descansa sobre todo en "las acciones de una cadena de agentes, cada uno de los cuales "traduce" [el mensaje] de acuerdo con sus proyectos", y "el poder se forja aquí y ahora enrolando a muchos actores en un esquema político y social dado" (LATOUR, 1986, p. 264 apud LONG, 2007, p. 50).
\end{abstract}

Em outras palavras, segundo Long (2007), a agencia (e o poder) depende de modo crucial do surgimento de uma rede de atores que devem ser parcialmente envolvidos em um "projeto" de alguma outra pessoa ou pessoas. A agencia, então, implica a geração e uso - ou manipulação - de redes de relações sociais e a canalização de elementos específicos (como demandas, ordens, bens, instrumentos e informação) através dos pontos nodais de interpretação e interação. Dessa forma, é essencial tomar conta das maneiras como os atores sociais se comprometem, ou são envolvidos em debates, acerca da atribuição de significados sociais a eventos particulares, ações e ideias.

\title{
5.1 A abordagem ator-rede
}

No âmbito das ciências sociais, a análise das redes sociais possui grande expressão, e não somente no nível da sociologia ${ }^{15}$ como também no da economia ${ }^{16}$, sobretudo por colocar o foco da análise no sistema de relações e fluxos, e não nos atores e seus atributos individuais; ao mesmo tempo, também questiona as estruturas sociais, quando concebidas

\footnotetext{
${ }^{14} \mathrm{O}$ conceito de ator não deve ser usado para denominar coletividades, aglomerações ou categorias sociais que não tem maneira de discernir para formular ou levar a cabo as decisões (HINDES apud LONG, 2007, p. 49).

${ }^{15}$ Granovetter (1985); Steiner (2006).

${ }^{16}$ North (1991; 1994); Paulet (2009).
} 
como externas, constrangedoras da ação e interação entre os atores individuais. Logo, é uma análise que se situa entre ação - estrutura.

Por exemplo, Granovetter (1985) propõe o conceito de rede social. As redes sociais limitam, mas também facilitam a ação dos indivíduos que as integram. O que é central nas redes sociais, de um ponto de vista teórico, é chamarem a atenção para a importância dos laços fracos, particularmente para a capacidade de promover um clima de confiança, tão necessário à ação coletiva.

Conforme Veiga (2005, p. 53-54), outros conceitos interessantes da abordagem atorrede são os de "tradução" e "ação à distância". Segundo Latour (1997, p. 10), "[...] a noção de tradução ou de rede é mais flexível que a noção de sistema, mais histórica que a de estrutura, mais empírica que a de complexidade e é a única que permite mediar o social e natural, o local e o global". O termo rede indica

que os recursos estão concentrados em alguns lugares - os nós - mas que estes nós estão ligados uns aos outros por malhas; graças a estas conexões os poucos recursos dispersos tornam-se num fio que parece estender-se por toda a parte (LATOR, 1995 apud VEIGA, 2005, p. 54).

Estas redes ou associações entre atores são redes de poder, nas quais alguns atores assumem posições mais importantes, constituindo os nós das redes, "pontos de passagem obrigatória", "centros de tradução". Nota-se que se introduziu o conceito de poder que, por ser importante para a análise da mudança nos espaços sociais, justifica pelo menos uma explicitação preliminar.

A noção de poder é decorrente dos conceitos de ação (agencia) e de interação. Primeiramente, a partir do conceito de ação, capacidade transformadora, introduz-se a noção de poder no sentido lato, poder definido somente como o uso de recursos de qualquer tipo, para se atingir produtos, fins. Por conseguinte, a partir do conceito de interação, introduz-se uma noção mais restrita e relacional de poder, tal como a capacidade de assegurar resultados, cuja realização depende da atividade de outros, sendo que poder, neste segundo sentido, equivale a dominação/dependência (alguns atores têm poder sobre os outros), mas não implicando necessariamente a existência de conflito, já que pode estar associado à solidariedade, à convergência (onde ambos os atores ganham) (VEIGA, 2005, p. 54). 
É esta noção de poder relacional ${ }^{17}$ que é adotada pela abordagem ator-rede. O poder, tal como já se concluiu para o conceito de estrutura, é também visto como um resultado das situações sociais, e não como uma causa que deriva de uma certa posição na estrutura social (MURDOCH, 1994 $\left.{ }^{18}\right)$.

Finalizando, sobre a forma como as redes são estendidas no espaço, introduz-se o conceito/noção de "ação a distância" à abordagem ator-rede. E a questão que se coloca é a de saber como os atores-chaves (nós de tomada de decisão, centros de tradução) atuam a distância sobre acontecimentos, lugares e pessoas que não são familiares, ou em termos de escala (local, global), o que liga atores locais a atores não locais, e como é que estes atores não locais afetam a mudança e controlam a distância (MURDOCH, 1994).

\section{Considerações finais}

O modelo de análise apresentado procura sintetizar contribuições retiradas de vários debates e teorias apresentadas, sugerindo-se uma abordagem fundamentada na diversidade, a qual envolve a temática da análise da mudança social a partir da abordagem ator-orientada.

Nesta reflexão, sugere-se que diversidade seja compreendida a partir da investigação da forma como os atores sociais tomam consciência dos seus interesses, formulam objetivos e definem estratégias para atingi-los, sobretudo em interação com outros atores presentes e/ou ausentes com influência no local. De tal processo, surgem redes de poder (associações), organizações e instituições que vão estruturando o espaço local.

Nas redes de poder (ou associações ${ }^{19}$ ), há atores que assumem papéis mais importantes que outros, constituindo-se pontos de passagem obrigatória (os nós das redes),

\footnotetext{
17 Poder sobre alguma coisa ou alguém é uma composição feita por muitas pessoas... atribuída a uma delas (LATOUR, 1986).

18 Se os atores derivam o poder da sua posição na estrutura social (membro de uma classe particular, grupo étnico ou sexo) então esta estrutura dá a explicação para todo o resto.

${ }^{19} \mathrm{O}$ conceito de associação que vem a ser utilizado é um conceito amplo, que se define não só como um certo tipo de grupo social, mas que, no caso da abordagem ator-rede, pode abranger também um híbrido de seres humanos e não humanos (textos, artefatos técnicos, dinheiro, etc.). Por grupo social entende-se um conjunto de pessoas que mantém relações sociais recíprocas e específicas. O grupo social tem uma dimensão objetiva, estrutural, regras e recursos, interesses e valores comuns, e uma dimensão subjetiva, de ação individual, aspirações e propósitos, que o situa no espaço/ tempo (VEIGA, 2005).
} 
quando conseguem, através de um processo de tradução, associar outros atores em torno de seus objetivos (tornados objetivos comuns), transformando-os em seus representantes.

\section{Referências}

ALBUQUERQUE, José Augusto Guilhon. Relações internacionais contemporâneas: a ordem mundial depois da Guerra Fria. Petrópolis: Vozes, 2005.

GIDDENS, Antthony. Novas regras do método sociológico. 2. ed. Lisboa: Trajectos, Gradiva, 1996.

GRANOVETTER, Mark. Economic action and social structure: the problem of embededdness. American Journal of Sociology, v. 91. n. 3. p. 481-510, nov. 1985.

KNORR-CETINA, Karin. The micro-sociological challenge of macro- -sociology: towards a reconstruction of social theory and methodology. In: KNORR-CETINA, K.; CICOUREL, A. V. Advances in social theory and methodology: toward an integration of micro-and macrosociologies. Boston: Routledge \& Kegan Paul, p. 1-47, 1981.

LATOUR, Bruno. The powers of association. In: LAW, Jonh (Org.). Power, action and belief, a new sociology of knowledge? Sociological Review Monograt 32. London: Routledge \& Kegan Paul, 1986. p. 264-280.

The Trouble with Actor-Network Theory. 1997. Disponível em <http://www.brunolatour.fr/sites/default/files/P-67\%20ACTOR-NETWORK.pdf>. Acesso em: 30 nov. 2016.

LONG, Norman. Sociología del desarrollo: una perspectiva centrada en el actor. Tradução de Horacia Fajardo, Magdalena Villarreal y Pastora Rodrígues. Mexico: El Colegio de San Luis, 2007.

LONG, Norman; PLOEG, Jan Douwe van der. Heterogeneity, actor and strusture: towards a recnstitution of the concept of structure. In: BOOTH, David (Org.). Rethinking Social Development: theory, research and practice. England: Longman, 1994. p. 62-9020.

MURDOCH, Jonathan. Weaving the seamless web: a consideration of network analysis and its potential application to the study of the rural economy. Working paper 3 -Centre for Rural Economy (CRE). United Kingdom: University of Newcastle upon Tyne, 1994.

20 LONG, Norman. Ploeg, Jan Douwe van der. Heterogeneidade, ator e estrutura: para a reconstituição do conceito de estrutura. England: Longman, p. 62-90, 1994. Extraído da tradução de Rita Pereira, Daniela Garcez e Leandro Krug Wives. 
NORTH, Douglass C. Economic performance through time. American Economic Review, 1994. v. 84, n. 3, p. 359-368.

Institutions. Journal of Economic Perspectives, 1991, v. 5, n. 1, p. 97-112. . Institutions, institutional change and economic development. Cambridge: Cambridge

University Press, 1990.

NUIJTEN, Monique; APPENDINI, Kirsten. El papel de las instituciones en contextos locales. Revista de la CEPAL. n. 76. abr., 2002.

PAULET, Jean-Pierre. A mundialização. Tradução de Celina Portocarrero. Rio de Janeiro: FGV, 2009.

PECQUEUR, Bernard (Org.). Dynamiques territoriales et mutations économiques. Paris:

L'Harmattan, 1996.

PECQUEUR, Bernard; SILVA, Mário Rui. Industrialisation diffuse et developpement. Estudos de Economia. v. IX. n. 4. jul./set., 1989.

REQUIER-DESJARDINS, Denis. Agro-Industria Rural y Sistemas Agroalimentares Localizados: Cuáles puestas? In: X Aniversario de PRODAR, Quito, nov. 1999.

STEINER, Philippe. A Sociologia Econômica. São Paulo: Atlas, 2006.

VEIGA, José Francisco Ferragolo da. Território e Desenvolvimento Local. Oeiras: Celta, 2005. 